\title{
Humor as a Tool of Analysis: Political Cartoons and Columns in Egyptian Newspapers
}

\section{Sara S. Elmaghraby}

Ph.D. in Journalism - Faculty of Mass Communication -

Cairo University

\section{Introduction:}

Humor helps understand social and political behavior and it is not common among scholars in Egypt and the Arab world. This paper aims at analyzing Humor in Egyptian Newspaper cartoons and columns in order to investigate the use of Humor Techniques in the Egyptian Press. It uses Humor as a tool of analysis that provides the researcher with qualitative data. Using a 9-coding scheme, this paper answers the questions of the themes of the humor, its content, its target and its aim and mainly its techniques. The results of this paper reveal a wide use of humor techniques among Egyptian cartoonists and columnists in different Egyptian newspapers as well a variety of themes, content, targets, and aims. 


\section{Introduction}

Among the numerous definitions of cartoons, one can categorize these definitions into three fields: firstly definitions of cartoons as interdisciplinary, secondly cartoons as a message of the communicator to the recipient, thirdly cartoons as differently defined in every science and fields. Although the definitions of cartoons vary tremendously among scholars, some common factors are present in these definitions. Cartoons are always actual, imageoriented, include commentary, critique and surely humor.

Three different aspects for analyzing cartoons are common among scholars: firstly the studying of political cartoons as visual commentaries and builders of opinion in journalism, secondly political cartoons as an artistic graphics process and thirdly- and most important for this paperpolitical cartoons as a satire or humorous format. (Knieper 2002) Although political cartoons are the most common journalistic formats that include humor and satire, it is surely not the only format. The second most important format is the columns that as well could include satire and humor.

In this paper, I mainly focus on the relation between political cartoons and columns on one side and humor on the other side. Previous research has widely studied political cartoons as a visual commentary and columns as verbal commentaries. They stressed their effect on building an opinion of recipients and shaping their attitudes and behaviors. The study of artistic and graphic elements though is studied heavily in the faculties of art and design and would neglect - from my point of view- the political and social role of political cartoons. Focusing on the analysis of humor will shed a light on a new dimension of analysis of political cartoons and columns and would help a better understanding of these interdisciplinary format. Holbert (2013) stated that political sarcasm has two major roles: Persuasion and Understanding (creating political knowledge). Therefore sarcasm, as well as satire, should have a positive effect on democracy to help build pluralism. Satire is also a very powerful art form used to critique specific human behaviors. It includes "Critique. (towards human behavior, vice, or folly, to convince the readers to view it disdainfully and thereby encourage a degree of social change), Irony (humor to point out the problems with the behavior being critiqued), Implicitness. (the critiqued behavior deconstructs itself within the satirical work by being obviously)". (LeBoeuf 2007) Humor, Sarcasm, and Satire are ways to express social and political terms in a critical way using an easy language full of metaphors and symbols. According to Meyer (2000), the aim of humor is Identification, clarification, differentiation, and enforcement. This paper will examine how Egyptian cartoonists apply the aims of humor and answer the question whether the four aims of humor are applied in the sample of this study. Lots of studies that dealt with satires, humor and sarcasm and their role in political engagement, in shaping the public opinion applying approaches such as Uses \& Gratifications and cultivation theory. Online surveys, content analysis, and interviews with the satirical producers were the 
المجلة العربية لبحوث الاعلام والاتصال - العدد ( •r ) - يناير / مارس - \ا•r

most common tools of analysis. Other studies focused on the development of satire in the United States e.g since the country was founded in 1776.(Wallachy 2016)

\section{Theoretical Approach: Humor Analysis}

Humor is a multi-disciplinary field of research. (psychology, philosophy, and linguistics, sociology and literature, computer science (or Artificial Intelligence) (Mulder and Najihult 2002) Definitions of humor are "manifold, ranging from a communicative activity with positive emotional reactions in perceivers to an individual trait (e.g., sense of humor, cheerfulness)". Humor is also defined as multidimensional because one must be able to produce, recognize, and appreciate the humor. Along with history, lots of humor theories were created from Aristotle, Plato, and Freud. The most common of these theories are the superiority theory, incongruity theory, and arousal-relief theory.

The debate whether the analysis of humor should be quantitative or qualitative did not end until today. On one hand, researchers suggested quantitative scale to measure humor. In his book, Ruch (1998) listed measurement tools for humor that included tools for every method (e.g., questionnaire, cartoon test, etc.). MesmerMagnus et al. (2012) provided as well a scale for humor and applied these scales on numerous studies. On the other hand, others suggested that qualitative research is characterized by a heavy dependence on data that are word-based and that humor primarily consists of words (spoken or written). They justified that humor analysis is qualitative as it could help understand social and political attitudes and behaviors.(Sen 2012) Only a little research in the Arab world adapts the humor analysis although it could help understanding cultural and social phenomenon whether national or cross-cultural. Humor analysis could also be applied to different societies in order to understand how societies differ in their humor due to societal, political and economic factors.

Academics have worked on creating categories for the analysis of humor that differed in number and in content. Berger (2017), for instance, suggested four main categories and 45 subcategories to help to analyze humor: 1language: facetiousness (dumbness), allusion, insults, definition, infantilism, exaggeration, irony, misunderstanding, sarcasm, satire, repartee, ridicule, bombast, wordplay, overliteralness. 2- logic: absurdity, analogy, disappointment, mistakes, catalog, coincidence, accident, reversal, rigidity, ignorance, theme and variation, repetition. 3- Identity: exposure, burlesque, unmasking, eccentricity, grotesque, imitation, scale, mimicry, parody, caricature, stereotype, impersonation, embarrassment, before and after 4- action: chase, slapstick, speed, time.

Poprawa (2013) suggested four types of satirical elements which are "Exaggeration: To enlarge, increase, or represent something beyond normal bounds so that it becomes ridiculous and its faults can be seen. Incongruity: To present things that are out of place or are absurd in relation to its surroundings. Reversal: To present the opposite of the normal order 
(e.g., the order of events, hierarchical order) and Parody: To imitate the techniques and/or style of some person, place, or thing."

This paper will base on the eleven techniques that were suggested by Roukes (1997) in his book "Humor in Art: A celebration of Visual Wit" to the analysis of humor. His categories look like the following:

- Association: the end result of combining elements together to create the cartoon through linking, combining, comparing elements together

-Transposition: the putting of an element in a different context, situation, time.

-Transformation: the changing of the composition of the subject, his form, his character

- Contradiction: the showing of the differences and the double meaning that could cause misunderstandings

- Exaggeration: the appearance of subjects in a bigger or a smaller, in a more beautiful or worse form etc. and distorting the reality

-parody:

- Punning: the giving of double meanings of image and text in order to create misunderstandings

-Disguise: the hiding of some elements and making them wear masks. instead of the missing information, symbols and metaphors are clarified.

- Satire: the irony and the creation of attention towards a certain topic clarifying the dumb, the immoral and the corrupt etc.

-Narration: the creation of a story or a myth through text and image
- Appropriation: the connotation between historical or well-known stories and citation with the recent cartoon.

\section{Problem Statement and Research Objectives}

While traditional newspaper formats are losing their readers, it became of utmost importance for the Egyptian media and newspapers to search for new maybe more attractive formats to use in their coverage and their opinion pieces. Political Sarcasm is gaining nowadays more readers and is becoming a very attractive tool in cartoons and columns around the world.

This paper aims at characterizing how Egyptian newspapers apply Humor not only in cartoons but in also in columns. I investigate the content of political cartoons and columns verbally and visually in order to come up with the characteristics of Humor in Egyptian newspaper during 2017.

\section{Research Questions}

RQ1- What are the themes that include humor in Egyptian newspapers?

RQ2- Who are the Target of the Humor in Egyptian newspapers?

RQ3- What are the humor techniques used in Egyptian Newspapers?

RQ4- What is humor trying to achieve in Egyptian Newspapers?

\section{Methodology}

To obtain the sample of the Political Sarcasm in the Egyptian newspapers and magazines, a scan on all Egyptian newspapers and magazines 
was done. I collected all Egyptian newspapers and magazines found at the bookstore for two days Wednesday the $6^{\text {th }}$ of September 2017 and Thursday the $7^{\text {th }}$ of September 2017. (Phase A). In (Phase B), newspapers and magazines were read carefully and opinion pieces that include Humor were collected. In this phase, some newspapers and magazines were excluded because they did not publish any. A total number of 10 newspapers and 3 magazines were chosen (Al Mosawar, Akher Saa, and Al Shabab). The 10 newspapers varied between governmental, private and partisan as follows: 3 of them governmental: Al Ahram, Al Akhbar, Al Gomhureya; 6 of them private: Al Youm Al Sabe, Almasry Alyoum,Al Sherouk, Al Watan, Al Bawaba, Sout Al Omma; 1 of them partisan: Al Wafd. A total number of 16 cartoons and columns were coded according to their formats: a- column b- cartoon. (Phase C) included a careful examination of the selected opinion pieces. A 9- category analysis scheme was created as follows:

1-Name of the newspaper

2-Date

3-Title

4- Context of Humor: the circumstances (e.g. political, societal etc.) in which humor is created 5- Theme of Humor: Story that the author is narrating

6- Content of Humor: The details of the story

7- Target of Humor: People or things that are an object of Humor

8- Techniques of Humor: Association, Transposition, Transformation, Contradiction, Exaggeration, Parody, Punning, Disguise,
Satire, Narration, and Appropriation.

9- Aim of humor: Introducing, Clarification, Differentiation, and Enforcement.

\section{Findings}

The Results of this paper revealed the use of different humor techniques that cartoonists used as well as a wide range of themes and targets. I will present here some Examples of columns and cartoons in order to explain the different uses of the humor techniques. In the explanations, lots of details are revealed about the categories of analysis mentioned in the Methodological Part of this paper.

\section{Fig.1. Example of a political column} that applies contradiction, exaggeration, punning and satire

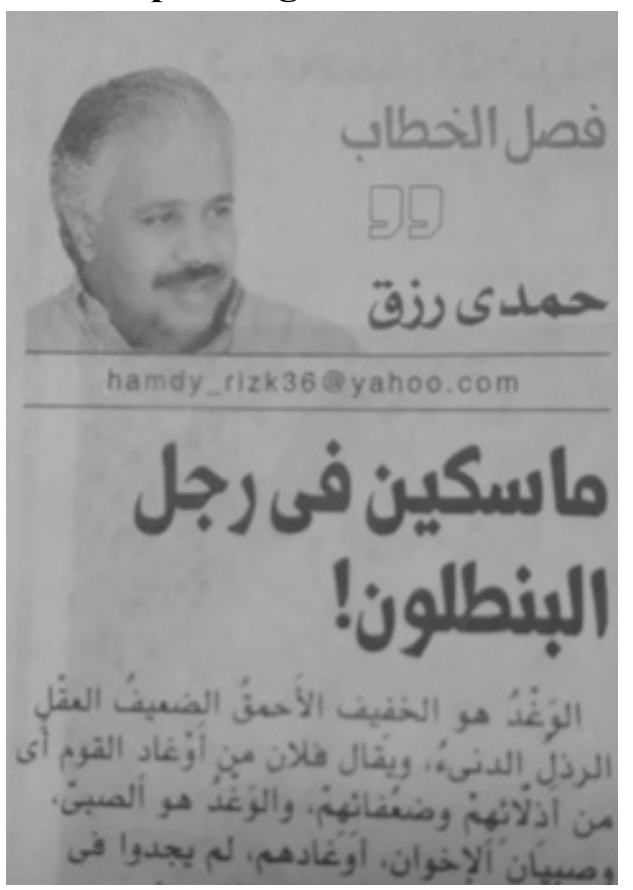


In Fig.1. the visit of the Egyptian President to BREXIT was presented with humor. The columnist Rizk describes the negative reactions of the Muslim Brotherhood on the president's visit. The Muslim Brotherhood has, according to Rizk, criticized the president while he was on his visit to a Brexit conference. Rizk, from his side, describes the Muslim Brotherhood as bastards, dumb and sons of the snakes. The target of the humor in this column is the Muslim Brotherhood and the former President who is affiliated with this group Mohamed Morsy. This former president was described as a spy, greedy, loves to eat, clumpy in his talks and his moves and after all a bad representation of Egypt. The context of this article is the visit of President El Sisi in a BREXIT conference. The content of this column is to criticize the reactions of the Muslim Brotherhood towards the visit of El Sisi. The techniques of humor applied in this column are a contradiction or the showing of the differences and the double meaning that could cause misunderstandings as for example comparing this president who is -according to the columnist neat and representable, with the former president Morsi who was dumb and not representable. Another technique of humor is an exaggeration. The columnist exaggerates the descriptions of Morsi and the Muslim Brotherhood by using extreme descriptions. Punning is also used and means the giving of double meanings of image and text in order to create misunderstandings such as using the words"they are holding in the pants legs" which means that they (the Muslim Brotherhood) are only taking care and focusing on less important details and neglect the main successes of the meeting of the president in BREXIT. The columnist also applies satire to create humor by describing Morsi and the Muslim Brotherhood as dumb and not loyal to the country and hoping for the failure of the state. (Rizk,07.09.2017)

\section{Fig.2. Example political column that applies association}

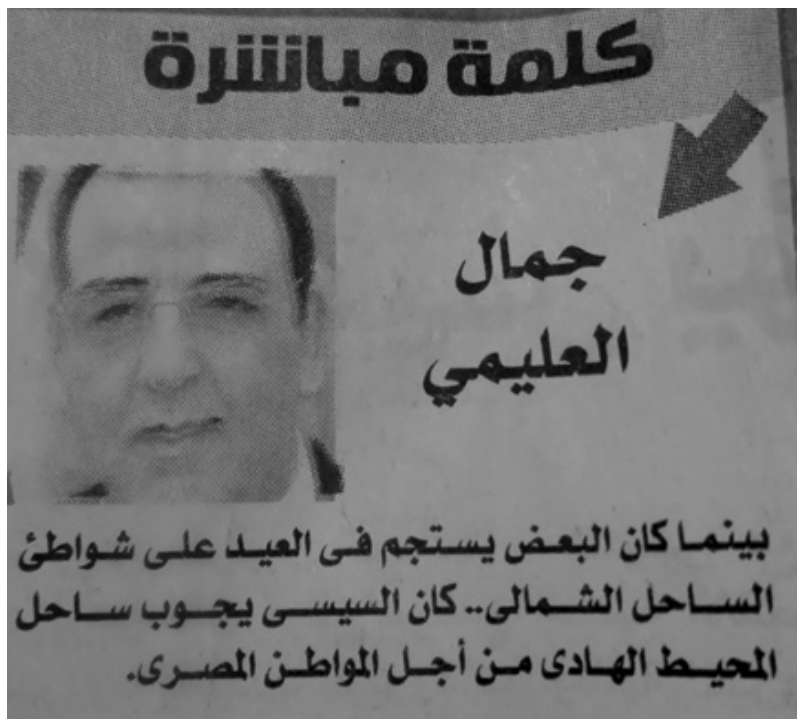

El Eleemy writes in (Fig.2.) in Al Mesa newspaper that "While Egyptians are spending their times on the North Coast, El Sisi is traveling to the Pacific Ocean for the sake of the Egyptians". The Association is used in this column to create humor. He compares what the people do and what their president does and links together the sea to show the contradiction and differences between the people and the president. The targets of this column are the Egyptian People. (Eleleemy, 07/09/2017) 
المجلة العربية لبحوث الاعلام والاتصال - العدد ( •r ) - يناير / مارس - \ا•r

Another cartoon published in Al Youm Al Sabee newspaper is mocking lazy governmental employees. These employees are presented sleeping on their desks while they have staples of unfinished work (files and papers ) on their offices. Although these employees are spending the whole day relaxing, they are still complaining about the amount of work they are doing. Contradiction or the showing of the differences and the double meaning that could cause misunderstandings these employees (the target) tell how much work they have done and how tired they are, while they are actually sleeping. This cartoon is a narration, as the cartoonist has created a story with text and image in which the reader can see how they are sleeping on their desks etc. the message in this cartoon would be the criticism of lazy employees who achieve too little. (Abdel Latif, 06/09/2017)

In Akher Saa magazine, the target of the humor is the corrupt employees. One of them goes to a psychiatrist in order to explain to him how sad he is that the government will end corruption and that he will lose so much money accordingly. Again here are the targets of the cartoon the employees but this time the corrupt not the lazy. The cartoonist uses the narration in order to create humor. The narration is obvious as there a story in this cartoon that the reader could imagine (the employee saw the new decisions that will end corruption- he is sad about these decisions - he goes to psychiatric in order to be healed from his sadness). The context of this cartoon is that the government has declared new decisions that aim at fighting corruption in governmental organization and the target of the cartoon are the corrupt employees who will be affected by these decisions.(Omar, 07/09/2017)

\section{Fig.3. Example Economic Cartoon that applies Wordplay, Contradiction, and Opposition}

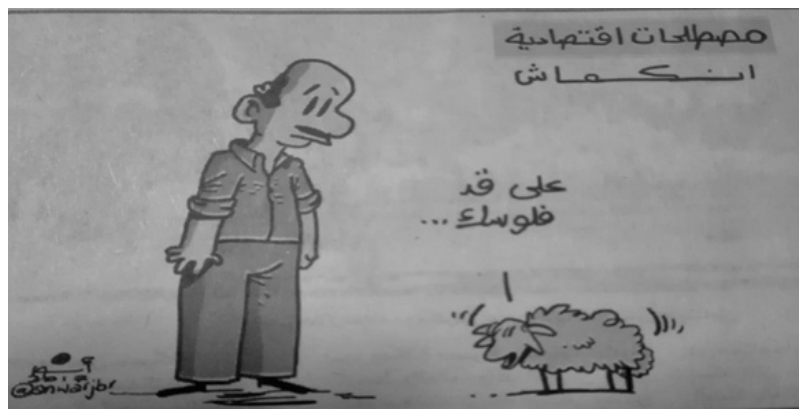

In Fig.3. the theme in this cartoon is economic. Humor is created through the contradiction, opposition, and wordplay. The Egyptian citizen is the target of the humor and is described as not capable of buying a sheep to slaughter for a celebration due to his economic circumstances. Therefore he is obliged to buy a very thin sheep. This situation is described by the cartoonist as " contraction or recession" which is an economic term but that the cartoonist uses in a different meaning ( the contraction or recession of the sheep that the man will buy for his feast). The context of this cartoon is the increasing prices of sheep and cows before the feast.(Unknown, 07/09/2017)

Another column -entitled " $1 / 4$ word" published in El Bawaba newspaper- describes the economic situation in Egypt by depicting Egyptian businessmen who refuse to pay the wages of the employees. "Businessmen in 
Egypt refuse to pay workers before the feast because they don't have the money. They would almost cry while they say: From where (shall we pay you)?". In this column, the message of the writer is justice and a fair treatment of labor. In this column, satire is used to create humor. The columnist is targeting the rich businessmen and describes how sad they are and how they would cry because they don't have the money, while in reality, they have the money. (Helmy, 06/09/2017)

Differentiation is very obvious in another cartoon by making a comparison between the prices of the pilgrim (Haj). "Businessmen who pilgrim and pay 400 thousand pounds would think that this will make them better people in comparison to poor people". The aim of this cartoon is to mock the great gaps between social class in Egyptian society. The target of this cartoon are the businessmen. This cartoon uses differentiation as well as the satire. Businessmen are compared to ordinary Egyptians and are depicted as dumb because they could get anything from God even forgiveness.(Selim,06/09/2017)

Another socio-economic cartoon explains the same feeling the father and the son have towards the start of the school. The father, from one side, is sad the school will open because of his incapability to pay the fees. His son from the other side is also sad because he does not want to attend classes and finish his vacations. The humor technique in this cartoon is the Association. The cartoonist has linked two situations and feelings together and combined them in order to create humor targeting the father and the son in Egyptian Society. (Gomaa, 07/09/2017)

In the same context (the beginning of the school semester ), another cartoon is entitled "Schools are on the doors" the cartoonist depicts an Egyptian citizen who goes insane because of school fees of his kid.(Youssef, 07/09/2017)

In Al Ahram, a cartoon describes the relationship between the private teacher and the student in an untraditional, classic way. The teacher- who should be respected by the student- is treated in this cartoon in a bad and humiliating way. The teacher though cannot answer back the humiliations. The technique that has created the humor in this cartoon is the transposition. The cartoonist has put the teacher in a new context and a new position than that the reader is expecting. The reader is expecting respect and obedience towards the teacher but is surprised with the different situation. (Farag,06/09/2017)

In a column entitled "What did I gain?", the writer uses sarcasm in criticizing the lack of hope among Egyptians and the spread of negativity towards the policy of the government. He describes the Egyptian society as unable to see the achievements of the government. He uses songs and famous slogans in his columns "My heart, you don't get comfortable and you don't relax" Etc. The aim of his column is to spread the feeling of hope and satisfaction among Egyptians. He expresses the importance of the words "Tomorrow is a better day". The recall of old songs and famous traditional Egyptian quotes is used in this column to create humor. This technique of humor is called appropriation 
المجلة العربية لبحوث الاعلام والاتصال - العدد ( • ) - يناير / مارس - ^|•r

and is used to arouse feelings and to convince the reader of a certain idea.(Rizk, 06/09/2017)

Fig.4. Example Cartoon applied Punning, Association, and Association

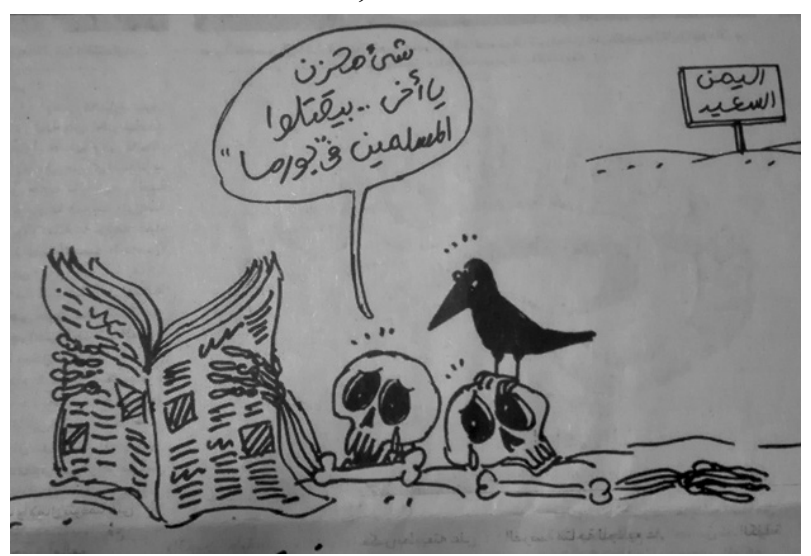

Skeletons are reading newspapers while buried in the sand in the "Happy Yemen" and say "It is very sad bro. The killing of Muslims in Burma." Association (Fig.4.) is used in this cartoon: the end result of combining elements together to create the cartoon through linking, combining, comparing elements together. Transposition is applied because skeletons in Yemen are feeling sad about what is happening in Burma and are sad about what happened to them. The punning is seen while these are skeletons and dead people they live in happy Yemen and them -although dead-are sad about the situation of the Muslims in Burma. Their situation themselves is not better.(Unknown,07/09/2017)

In a cartoon of Amro Selim published in Al Akhbar, the cartoonist describes the President of Qatar and his wife as willing to get rid of their image that supports terrorism. They want to wash off all the dirt their regime has done. Therefore they seek help from a US company to change their negative image. The target of this cartoon is the Qatari regime by drawing a huge number of chloride are unable to clean the "dirt". Satire is the technique of humor used in this cartoon. The cartoonist is clarifying how dumb the Qatari regime is. As they think that they could wash their country reputation in a washing machine, while they are even dumber to wash it by themselves that they need any assistance from the USA. (Fahmy, 06/09/2017)

Fig.5. Example Column applied punning

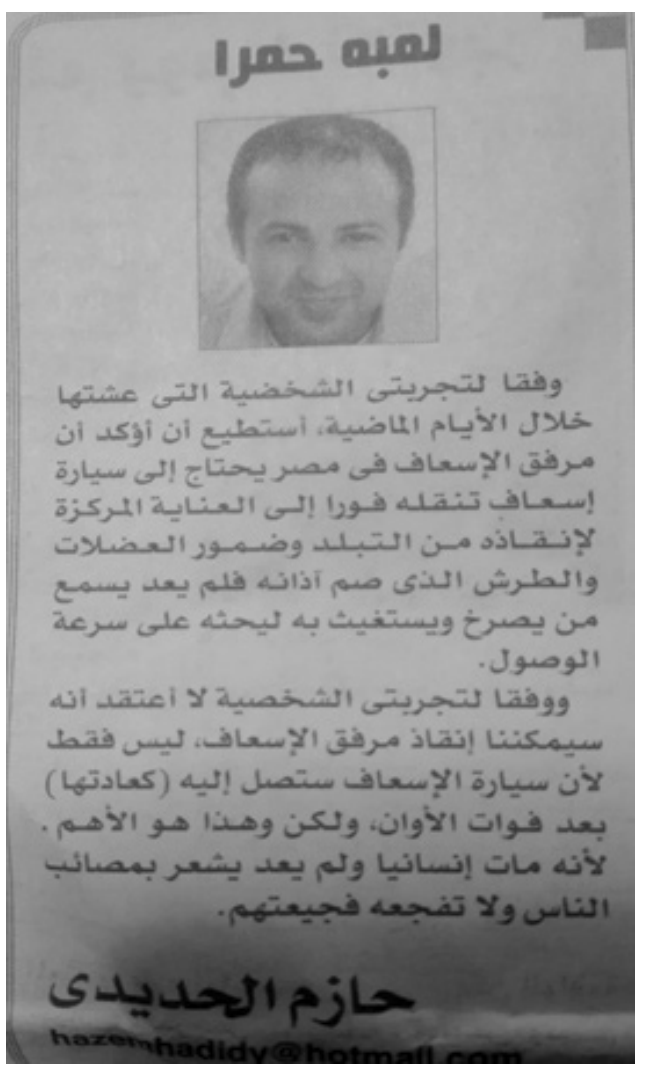


In a column entitled "The Red Lamp," the author says "the ambulance in Egypt needs an ambulance itself "to show the bad circumstances of the health sector in Egypt. "The ambulance needs an ambulance to rescue it from some illnesses that make It not function properly" This is the message of this column and is a clear example for punning which means the giving of double meanings of image and text in order to create misunderstandings. the Context a situation the writer faced with the ambulance last week and the target - who or what it is directed at the ambulance in Egypt. (Elhadidi,07/09/2017)

The medical sector was also criticized in the sample study. In a column, the story of a doctor and a university professor in the Faculty of medicine is narrated. They were corrupt and spoiled by money and power and turned to be a bad example. (Elgendy,06/09/2017)

Fig.5. Example Column applied Satire and Appropriation

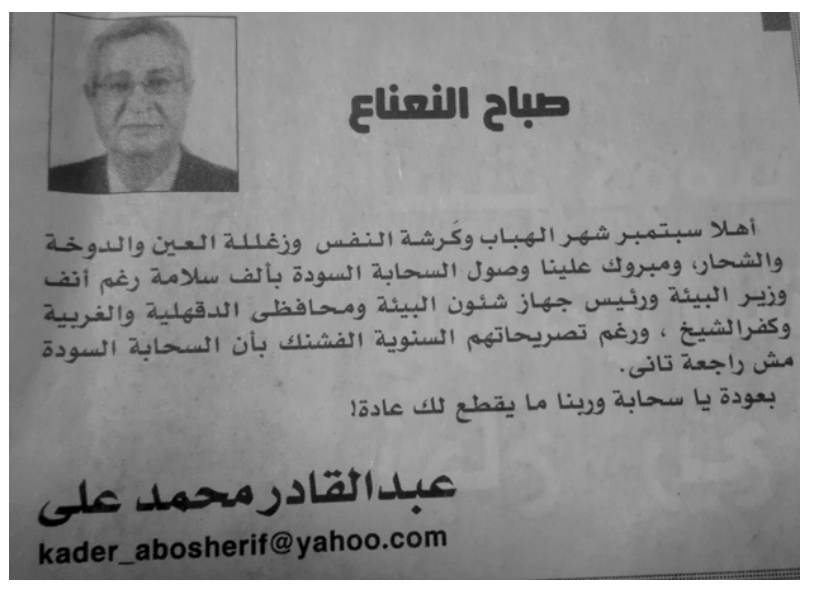

The statements the ministers are giving about the black cloud is all wrong and here we see how the black cloud is coming back. The contradiction between the statement given by the ministers and the reality is explained here. Satire is shown in Fig.5. which means the irony and the creation of attention towards a certain topic clarifying someone who is hiding the truth from the target of this humor who are the ministers. They give -according to the writerfake statements about the environment. The columnist uses Appropriation, and links a quote the Egyptians slang differently: Welcome back Black cloud!!” (Ali, 07/09/2017)

\section{Conclusion}

This paper concluded that the Egyptian cartoonists used all kinds of the techniques of humor suggested from Ruch (1998). The themes that included Humor in the sample of the study varied between political, economic, social, medical, environmental, educational and foreign affairs. Cartoons and Columns applied contradiction, for instance, between businessmen and bourgouise and between the president and the former president. This paper concluded that the main targets of the humor in columns and cartoons were President Al Sisi, Egyptian Bourgouise, Political Activists, Businessmen, Muslim Brotherhood.

The language used in the political sarcasm articles sample of the study is characterized as easy, clear and direct. Slang was used heavily in political sarcasm as well as part 
المجلة العربية لبحوث الاعلام والاتصال - العدد ( •r ) - يناير / مارس - \ا•r

of the popular culture such as sings, films, quotes etc. In some cases, the language used by authors and cartoonists used some bad words and insults towards the target. Exaggeration was also used in some of the analyzed opinion pieces. Metaphors were also used and wordplay to create verbal humor in the sample of the study

This paper agrees with the four aims of humor suggested by Meyer (2000) and answers the question whether Egyptian cartoons include these aims. Results show that Identification was clear especially to introduce the importance of hope in some columns. The Clarification was also present is explaining the problems Egyptian people suffer from due to their economic status. In the column (see Fig.1.), Differentiation is applied in pointing at the differences between the current president and his government and the last president of the Muslim Brotherhood. Enforcement was used as well by cartoonists to explain the importance of positivity and fighting corruption.

\section{Limitations and Further research}

As explained in this paper, this paper adapts only the humor techniques suggested by Ruch 1998. It is worth to study the other and most recent humor analysis techniques suggested by other scholars. Quantitative research could be applied as well in order to gain some numbers and rankings related to the use of these techniques in cartoons and columns. Studies on Readers and Audiences should be conducted for further research in order to analyze their preferences and the readability of Political Sarcasm Article in Egyptian Newspapers and Magazines. Studies on how the readers receive and decode political sarcasm in Egyptian press should be enhanced. Furthermore, studies about journalists as well as cartoonists responsible for creating the political sarcasm in Egyptian newspapers could be conducted. A comparative study that compares political sarcasm in the Egyptian media system with political sarcasm in other media systems could be expanded.

\section{Bibliography}

(1) Abdel Latif, Mohamed, Cartoon, El Youm Elsabee,p.15, Wednesday 06/09/2017

(2)Ali, Abdel Kader, Good Morning Peppermint, Al Akhbar, p.14 Thursday 07/09/2017

(3)Berger, ArthurAsa (2017) AnAnatomy of Humor, retrieved in https://books.google.de/ books? $\mathrm{id}=0 \mathrm{TgrDwAAQBAJ} \&$ printsec $=$ fron tcover\&dq=inauthor:\%22Arthur+Asa+Berg er\%22\&hl=de\&sa $=$ X\&ved $=0$ ahUKEwiS0Y 7hqurYAhWO-aQKHSkqBU4Q6AEISTAE

(4)Elhadidi, Hazem, Red Lamp, Al Akhbar, p. 15 , Thursday 07/09/2017

(5)El Eleemy, Gamal, Direct word, Al Mesa, p. 2, Thursday 07/09/2017

(6)Elgendy, Ayman, Whispers, Lots of Love, Space for Opinion, p.12 Wednesday 06/09/2017 
(7)Fahmy, Amro, The Qatari Regime work with a US company to clean his image from supporting terror, Al Akhbar, Last page, Wednesday 06/09/2017

(8)Farag, Hassan , World of Caricature, Al Ahram, p. 9 Wednesday 06/09/2017

(9)Gomaa, Caricature, Al Fagr, p. 15, Thursday $\quad 07 / 09 / 2017$

(10)Helmy, Mohamed, 1/4 word, Elbawaba, page 2, Wednesday, 06/09/2017

(11)Holbert, Lance R. (2013) Developing a Normative Approach to Political Satire: An Empirical Perspective. International Journal of Communication, p. 7, $305-323$ retrieved in ijoc.org/index.php/ijoc/article/ download/1933/855

(12)Knieper, Thomas (2002) Die Politische Karikatur: Eine journalistische Darstellungsform und deren Produzenten, Herbert von Halem Verlag (in German) p.75 (13)LeBoeuf, Megan, (2007), The Power of Ridicule: An Analysis of Satire, the University of Rhode Island, retrieved in http://digitalcommons.uri.edu/srhonorsprog

(14)Matsa, Katerina-Eva ( 2010) Laughing at Politics: Effects of Television Satire on Political Engagement in Greece, A Thesis submitted to the Faculty of the Graduate School of Arts and Sciences of Georgetown University in partial fulfillment of the requirements for the degree of Master of Arts in Communication, Culture and Technology, Washington, DC

(15)Meyer, J. C. (2000) Humor as a double- edged sword: Four Functions of Humor in Communication, Communication Theory, 10(3), 310-331

(16)Mesmer-Magnus, Jessica, Glew, David and Viswesvaran (2012) "A metaanalysis of positive humor in the workplace", Journal of Managerial Psychology, Vol. 27 Issue: 2, pp.155-190, retrieved in http://www.emeraldinsight.com/doi/ abs/10.1108/02683941211199554

(17)Mulder, MP and Nijholt, A.(2002) Humour Research: State of the Art, Center for Telematics and Information Technology, TKI-Parlevink Research Group, the University of Twente, retrieved in https:// research.utwente.nl/en/publications/ humour-research-state-of-art

(18)Omar, Mohamed, Cartoon, Smile, Akher Saa, Thursday 07/09/2017

(19)Poprawa, Marcin,(2013) Polish political humor. An outline of the phenomenon. doi:10.7592/EP.1.poprawa retrieved in https://www.researchgate.net/ publication/299735192_Polish_political humour An outline of the phenomenon (20)Rizk, Hamdy, Holding in the Pants Legs, The End of the Discourse, Space for Opinion, p. 13, Almasry Alyoum, Thursday, 07/09/2017

(21)Rizk, Hamdy, What did I gan, Column, AlAkhbar, Last Page, Wednesday 06/09/2017

(22)Roukes, Nicolas (1997) Humor in Art: A celebration of Visual Wit retrieved in https://www.amazon.com/Humor-ArtCelebration-Visual-Wit/dp/0871923041 
المجلة العربية لبحوث الاعلام والاتصال - العدد ( •r ) - يناير / مارس - \ا•r

(23)Ruch, Willibald (1998) The Sense of Humor: Explorations of a Personality Characteristic, retrieved in https://books. google.de/books/about/The Sense of Humor.html?id=v7e68zFtmRsC\&redir $\underline{\mathrm{esc}}=\mathrm{y}$

(24)Scheel, Tabea et al.( 2017) Definitions, Theories, and Measurement of Humor, Chapter two (in) Scheel, Tabea, Gockel, Chritine (2017) Humor at Work in Teams, Leadership, Negotiations, Learning and Health, Springer Verlag, retrieved in http:// www.springer.com/978-3-319-65689-2

(25)Selim, Amro, Caricature, Almasry A1 Youm, Wednesday 06/09/2017

(26)Sen, Anindya (2012) Humour Analysis and Qualitative Research, Social Research Update, Issue 63, retrieved in http://sru.soc. surrey.ac.uk/SRU63.pdf

(27)Stanel, Tina (2006) Linguistic Approaches to Irony- an Analysis of British Newspaper Comments, Technische Universitat Chemnitz, Philosophische Fakultat, Magisterarbeit, retrieved in https://www.tu-chemnitz.de/phil/english/ sections/linguist/documents/stanel lingapproachesirony.pdf

(28)Unknown, Caricature, Economic terms, Al Masry Al youm, Thursday, p.6, $07 / 09 / 2017$

(29)Unknown, Cartoon, Happy Yemen, Almasry Alyoum, p.13 Thursday 07/09/2017

(30)Wallachy, Alexandra (2016) The Evolution and Importance of News Satire, A Thesis Presented to the Department of Journalism and the Robert D. Clark Honors College in partial fulfillment of the requirements for the degree ofBachelor of Arts Retrieved in https://scholarsbank.uoregon. edu/xmlui/bitstream/handle/1794/20384/ Final\%20Thesis-Wallachy.pdf

(31)Youssef, Tamer, School are on the doors, Cartoon, p. 10, Al Ahram, Thursday 07/09/2017 